\title{
THE MANAGEMENT OF RIGHT SUPRAHEPATIC ABSCESS
}

By F. G. SMIdDy, F.R.C.S.

Department of Surgery, General Infirmary at Leeds

A subphrenic abscess may be defined as a collection of pus lying between the diaphragm and the transverse mesocolon. It is the purpose of this paper to discuss the treatment and management of abscesses occurring in the right suprahepatic compartment which is the space most commonly involved. Such abscesses are fortunately rare since the mortality rate in recorded series is high. Ochsner and DeBakey (1938) in 932 collected cases found the mortality rate of this complication to be $30 \%$ and Harley writing in Maingot's Management of Abdominal Operations recorded 75 deaths in a series of 188 patients. Subphrenic abscesses arise most commonly following perforation of a peptic ulcer, acute appendicitis complicated by peritonitis and operations on the biliary system, but any abdominal catastrophe or operation accompanied by infection may be followed by this condition.

\section{Aetiology and Location}

The primary concern of this paper is the management of those abscesses occurring in the right suprahepatic space. In all, from the general medical and surgical records of this hospital 32 patients have been noted as developing a subphrenic abscess in the years $195^{\circ}$ to 1955 inclusive. Of these 32 patients, six died as a direct result of this complication, a mortality of $20 \%$. The primary aetiological factor is shown in Table $I$. Of the particular space infected the majority (22) occurred in the right suprahepatic space, with the remaining four intraperitoneal spaces sharing equally in the number remaining. The predominance of the right suprahepatic space is in accordance with previously published figures.

\begin{tabular}{|c|c|c|c|c|}
\hline \multicolumn{5}{|c|}{ Table I } \\
\hline Perforated peptic ulcer & & . . & $\cdots$ & 12 \\
\hline Acute appendicitis & & $\ldots$ & $\ldots$ & IO \\
\hline Cholecystectomy \pm op & erations & $s$ on & the & \\
\hline CBD. . . . & $\ldots$ & $\ldots$ & . & 4 \\
\hline Partial gastrectomy & . & . & .. & 2 \\
\hline Pancreatitis $\quad \ldots$ & . & . & . & $\mathbf{I}$ \\
\hline Perforation of colon & & .. & . & 2 \\
\hline Traumatic rupture of & & To & $\because$ & $32 \stackrel{\text { patients }}{ }$ \\
\hline
\end{tabular}

The Anatomy of the Right Suprahepatic Space

The anatomical boundaries of the right supraj hepatic space are as follows:-

Anteriorly: The anterior border of the live् where the space becomes continuous with the general peritoneal cavity.

Medially: The falciform ligament.

Posteriorly: The anterior reflection of the right coronary ligament.

Laterally: The space becomes continuous with the right paracolic gutter at the infero-latera border of the liver.

Two features of anatomical significance a seldom appreciated; firstly, the position of the anterior reflection of the right coronary ligamerent which lies posteriorly, forming, as Harley (I 9 ) described, a hinge on which the liver rotes downwards when a pneumoperitoneum or supfr hepatic abscess is present. Figure I demonstrat a right suprahepatic abscess with elevation of the diaphragm and rotation of the liver downwards from this posterior hinge. Secondly, the rigle suprahepatic space in the adult extending from the anterior to the posterio-inferior border of the liver covers a vast area. Measurements in the cadaver show the average surface area of this space to be $75 \pm 5 \mathrm{sq}$. in. The surface area of the adult human hand measured from the wrist joint is approximately $36 \mathrm{sq}$. in. This incmediately suggests that even with accurae radiological localization of the abscess cavity any method of exploration of this space which does net permit of adequate access to the whole area of the compartment is unsuitable in the majority of patients.

\section{Diagnosis}

When pyrexia, usually without physical signs develops following operation or in an acuffe abdominal catastrophe under conservative treas ment a subphrenic abscess should be suspectee Pyrexia may occur at a variable interval following operation but seldom earlier than the eighth daథ̄. The abscess can remain latent for a long periog, 


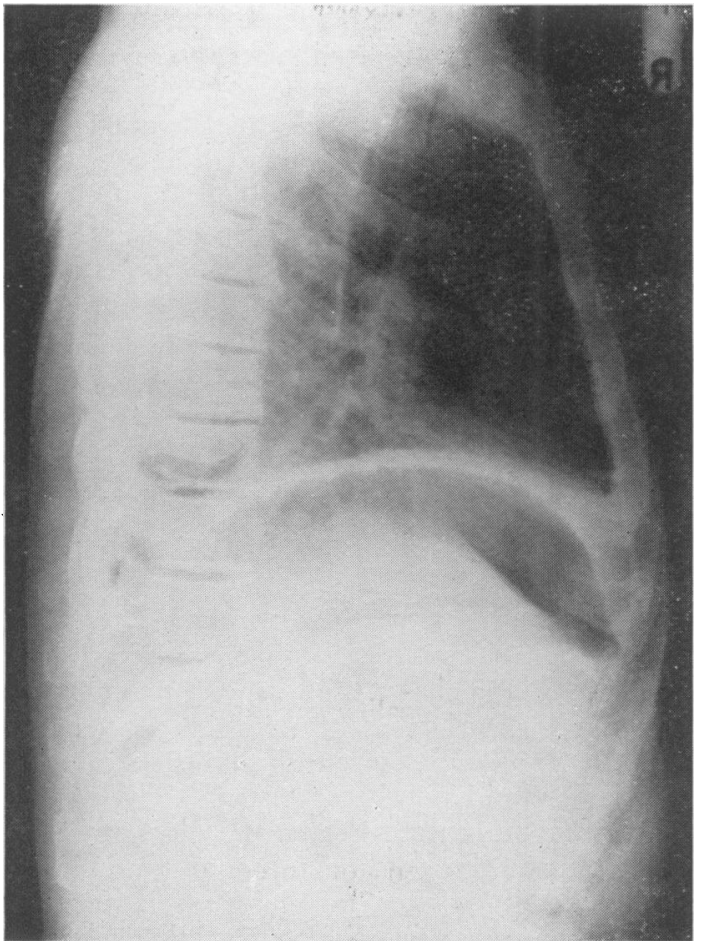

FIG. I.-Right suprahepatic abscess showing right diaphragm raised and liver rotating downwards on the posterior abdominal wall. Collapse of right lower lobe.

the longest interval in this series being one year; in this patient a perforated duodenal ulcer was treated by suture with apparent recovery. One year later a pneumonic illness occurred during which the patient produced large quantities of purulent sputum; investigation revealed a right suprahepatic abscess.

Once suspicion has been aroused, radiological methods take precedence over other diagnostic aids, screening to determine the mobility of the diaphragm being an essential part of this examination together with P.A. and lateral views of the chest and subdiaphragmatic areas to determine the position of the abscess relative to the anteroposterior plane. On the left side a barium meal will often aid in precise localization by demonstrating the effects of extrinsic pressure on the stomach, the diaphragm on the left side tending not to rise so readily as on the right.

\section{Treatment}

An established suprahepatic abscess requires drainage. An established abscess may be demonstrated by continuous pyrexia in spite of adequate and appropriate antibiotic therapy or by a sub-

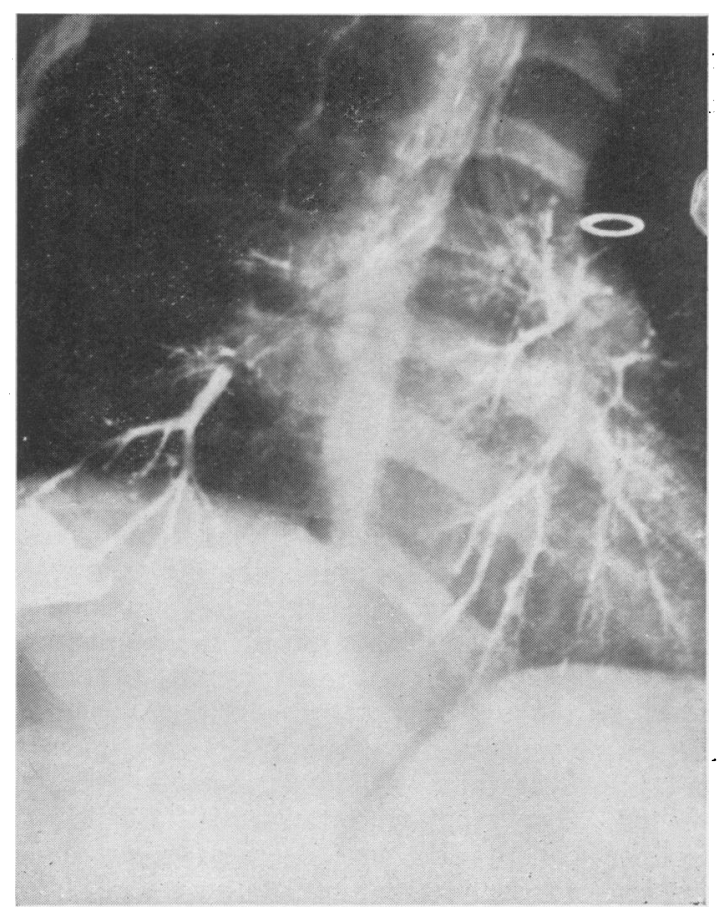

FIG. 2.-Sinogram showing bronchial fistula following drainage of right suprahepatic space due to tube erosion of the diaphragm, sinogram performed 36 hours after initial operation.

diaphragmatic fluid level on first recognition of this complication. Two methods of exploration of the right suprahepatic space have been described; firstly, the extraserous route either anterior or posterior and secondly, the transpleural approach passing through the bed of the 8th or 9th rib. In this series of 22 abscesses in the right suprahepatic space the extraserous approach has been used in ten patients and the transpleural in twelve.

The transpleural approach is made through the bed of the 8th or 9th rib, sufficient rib is removed to allow the whole hand to be inserted through the wound, the parietal pleura is incised and as a preliminary step an underwater drain is inserted into the pleural cavity. The incised parietal pleura is then stitched to the diaphragmatic pleura, diaphragm and parietal peritoneum are then opened and the abscess exposed. Following careful toilet of the abscess cavity including a positive search for loculi, the cavity is drained in dependent fashion, the drainage tube being connected with an underwater seal.

\section{Post Operative Management}

The post operative management of the abscess 
begins with the correct placing of the tube at the initial operation. Drainage must be dependent and the tube used should be of adequate bore and reasonably soft in consistency. Too hard a tube placed too high in the cavity results in inadequate drainage of the cavity and predisposes to perforation of the diaphragm. Fig. 2 demonstrates a bronchial fistula developing within 36 hours of tube drainage, the only clinical sign of this complication being an increase in the amount of sputum 24 hours following drainage; withdrawal of the tube produced spontaneous healing of the fistula.

Chest physiotherapy should begin immediately the patient is co-operative. This will aid depression of the diaphragm, diminishing the cavity size and assist the expansion of the lower lobe if collapse or infection has occurred prior to operation. The post operative management of the tube is of paramount importance. Sinograms performed at weekly intervals will indicate how far and how fast tube withdrawal may be accomplished. Too rapid withdrawal of the tube will produce collapse of the cavity at some point proximal to the termination of the track. This will usually produce an immediate response; the general condition of the patient will deteriorate, temperature and pulse rate will rise. This complication demands reinsertion of this tube which is best performed by dilating the track with graduated soft rubber catheters until the drainage tube can be reinserted to the full length of the cavity. Sinography should be performed by withdrawal of the drainage tube and the introduction of the Lipiodol through a small soft rubber catheter, rotating the patient so that all ramifications of the cavity are filled and demonstrated. If Lipiodol is introduced directly through the drainage tube, there is a danger of air embolus; further the cavity and its ramifications may be inadequately filled. Following sinography a withdrawal of the tube may be indicated if the cavity has closed about it. This may be performed at an average of one inch per week, any rise in temperature being a positive indication for reinsertion under general anaesthesia.

\section{Results of Treatment}

The twenty-two patients presented in this review with abscesses in the right suprahepatic space are divisible into two groups according to the mode of drainage. Ten patients were treated by the extraserous approach. Of this number two died following operation, one patient drained for 13 years until the cavity was reexplored by the transpleural method, one patient drained for two years and two patients drained for periods up to one year.
Twelve patients were treated by the transpleura approach with no mortality. In two cases a empyema was already present at the time of the initial drainage. Both empyemata were initiall treated by aspiration following drainage of the suprahepatic abscess but later required a decortica tion. Neither of these empyemata can be re $\stackrel{p}{?}$ garded as a complication of the method since bot? were already present at the time of drainage. The time required for the sinus to close was variable but did not exceed three months and in the majority of cases six weeks elapsed betweeक्क drainage and full recovery.

\section{Discussion}

It has frequently been emphasized that an abscess need not necessarily follow infection of the subphrenic spaces. It is probable that with modern antibiotic agents many abscesses are़ aborted. Fig. 3 shows the temperature chart and radiographs of a boy 12 years of age who, on the eighth day following appendicectomy developedo pyrexia without localizing signs. Twenty-fous hours after the onset of fever the diaphragm was screened and the right diaphragm found to be raised and immobile; no fluid level was seen however, and a course of chloromycetin 250 mgms. six hourly was given for three days leading $g \circ c^{\circ}$ complete apyrexia six days later with a return screening to full diaphragmatic mobility.

Once an abscess has become establishes drainage is imperative to avoid intrathoracic complications, the commonest of which are empyema, bronchial fistula, pulmonary infection and, rarely, gangrene of the lower lobe.

In this group of patients two methods of treatment are compared, the classical approaches? to the suprahepatic space have been used in teno patients and the transpleural approach in twelve $-\bar{\partial}$ The posterior extraserous approach described bye. Nather and Ochsner (1923) and the anterior: subcostal approach of Clairmont and Meyer. (I926) have been widely employed for drainage of the suprahepatic space. The popularity of these methods has been due to fear of empyema음 developing if the pleura is opened during operation. Harley (1955) in a collected series of 129 patients found the mortality rate using extraserous drainagen (44 patients) to be $9.1 \%$, transperitoneal drainage (45 patients) $37.8 \%$ and transpleural drainage $N$ (40 patients) $25 \%$. The arguments against thew transpleural approach, therefore, are the higho mortality rate and the frequency with whicho pleural infection is said to follow this mode of exposure. Doherty and Rowlands (193 I) were ? $^{\text {? }}$ concerned by the frequency by which empyemata developed after transpleural explorations had been performed. 

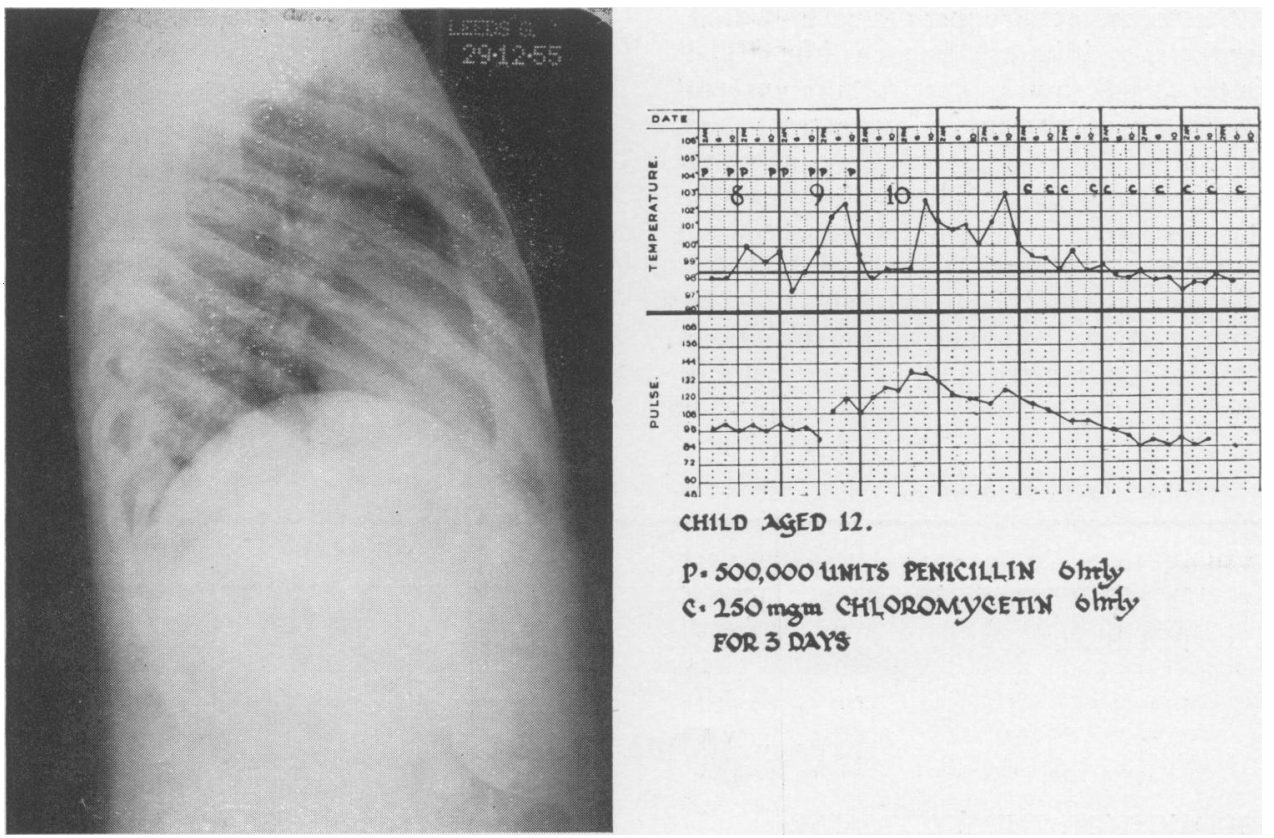

CHILD AGED 12.

p. 500,000 UNITS PENICILLIN Ohtly

C. $250 \mathrm{mgm}$ CHLOROMYCETIN ohrly FOR 3 DAYS

FIG. 3.- Right suprahepatic infection. Child, aged 12 years. Appendicectomy with peritoni،is. Right diaphragm raised and immobile. Successfully treated with Chloromycetin.

Many of the statistics notably those of Ochsner and Graves (1933) and Ochsner and DeBakey (1938) condemning this approach were collected before antibiotics were in common use and before the great importance of post operative management of these patients was appreciated. On anatomical grounds the transpleural approach is superior to the extraserous methods, direct as opposed to blind access is obtained and the abscess cavity can be thoroughly explored. The importance of thorough exploration of the cavity is demonstrated by the results obtained in the group treated by the extraserous route. In four patients prolonged discharge followed this method of drainage. A discharging sinus is a constant threat since closure of the track may lead to the further extension of the residual abscess with subsequent intrathoracic complications. The only clear indication for an extraserous approach to the right subphrenic space is in those patients who present with definite localizing signs in the right upper abdomen and in addition a palpable mass. Only three abscesses of this type have been encountered in the present series; in these patients an anterior subcostal incision will provide adequate exploration and drainage. In the absence of localizing signs the transpleural approach allows exploration of the whole area of the suprahepatic space. Experience has shown that if the lung is kept fully expanded and the operation is covered by the correct antibiotic, empyemata do not occur; if an empyema is already present this can be dealt with simultaneously. Diagnostic aspiration has not been used in this series of patient, the difficulties and dangers of finding the abscess with the needle outweighing any advantage which may be gained in the occasional case where positive aspiration is obtained.

It would appear from a study of the patients presented here that the reduction in mortality rate in this condition is dependent on the early recognition of the abscess before pulmonary and pleural complications have occurred. The use of the transpleural method of drainage would appear to reduce the morbidity and may well reduce the mortality associated with this condition; it does not appear in the patients treated in this series to have been productive of pleural complications.

\section{Summary}

I. A series of twenty-two cases of suprahepatic abscess secondary to intra-abdominal sepsis has been reviewed.

2. Two methods of treatment have been adopted, the extraserous and the transpleural approach. The operative technique of transpleural exploration has been described.

3. The post operative management following drainage has been described.

4. The results obtained by using these methods 
suggest the transpleural approach is better in reducing the morbidity of this condition. The series is too small to consider the influence of either approach on the mortality rate.

5. A patient suffering from a subphrenic infection has been described which responded to adequate antibiotic therapy.

My thanks are due to Mr. G. Armitage, Mr. D. Chamberlain, Mr. A. J. C. Latchmore, Mr. H. S. Shucksmith and Mr. G. Wooller, who allowed me to treat some of their cases and to review their records.
REFERENCES.

I. CLAIRMONT, P., and MEYER, M. (1926), Acta. chir. scnd, 60, 55 .

2. DOUGHERTY, W. D., and ROWLAND, R. P. (193I), Brit. Med.f., i, 168 .

3. HARLEY, H. R.S. (1949), Thorax. 4.

4. HARLEY, H. R. S. (1953), 'The Management of AbdominalOperations,' 963. Lewis, London.

5. HARLEY, H. R. S. (1955)' Annals of R.C.S., England., 17, 201

6. NATHER, C. and OCHSNER, E. W. A. (1923), Surg. Gynec. Obstet., 37, 665 . 7. OCHSNER, A. and deBAKEY, N. (1938), Surg. Gynec. Obstet
66, 426 .

8. OCHSNER, A. and GRAVE, A. N. (1933), Annals of Surg. ,98, $96 \mathrm{I}$.

\section{RHEUMATIC DISORDERS}

(Postgraduate Medical Journal)

Price 3s. 10d. post free

INTRODUCTION: THE RHEUMATIC
DISEASES

F. Dudley Hart, M.D., F.R.C.P.

\section{RECENT ADVANCES IN THE PATHOLOGY OF CHRONIC ARTHRITIS AND RHEU- MATIC DISORDERS}

D. H. Collins, O.B.E., M.D., M.R.C.P.

\section{RHEUMATOID ARTHRITIS}

J. J. R. DuthIE, F.R.C.P.E.

\section{OSTEOARTHRITIS}

G. C. Lloyd-Roberts, M.B., F.R.C.S.

\section{GOUT}

R. M. Mason, D.M., M.R.C.P.

\section{THE RARER ARTHROPATHIES}

F. Dudley HaRT, M.D., F.R.C.P.

PHYSICAL METHODS IN THE TREATMENT OF RHEUMATIC DISORDERS

W. S. TEgNeR, F.R.C.P.

THE SURGERY OF RHEUMATIC DISEASE

JoHN Bastow, M.D., F.R.C.S.

Published by

THE FELLOWSHIP OF POSTGRADUATE MEDICINE 60, Portland Place, London, W.1

\section{NOTICE OF SPECIAL INTEREST TO SUBSCRIBERS:} "WHY NOT HAVE YOUR COPIES OF THIS
JOURNAL BOUND INTO YEARLY VOLUMES?"

Arrangements have now been made to have the twelve monthly issues fully bound in dark green pin head cloth, lettered in gilt on spine with name of lournal, Volume Number and year, complete with index at front, 19s. 6d. per Volume, post free. A limited number of out of print journals are available to bind into volumes and make your library complete. Price on application giving details of issues required to complete back volumes.

the fellowship Of postgraduate medicine 60 PORTLAND PLACE, LONDON, W.I
WHY NOT

HAVE YOUR

JOURNALS

BOUND? 